Article

\title{
The Different Clinicopathological Features of Remnant Gastric Cancer Depending on Initial Disease of Partial Gastrectomy
}

\author{
Won Ho Han ${ }^{1}{ }^{\mathbb{D}}$, Bang Wool Eom ${ }^{1}$, Hong Man Yoon ${ }^{1}$, Young-Woo Kim ${ }^{1,2}$, \\ Myeong-Cherl Kook ${ }^{1, *,+}$ and Keun Won Ryu ${ }^{1, *,+}$ \\ 1 Center for Gastric Cancer, National Cancer Center, Goyang 10322, Korea; 13408@ncc.re.kr (W.H.H.); \\ kneeling79@ncc.re.kr (B.W.E.); red10000@ncc.re.kr (H.M.Y.); gskim@ncc.re.kr (Y.-W.K.) \\ 2 Department of Cancer Control and Population Health, National cancer Center Graduate School of Cancer \\ Science and Policy \& Center for Gastric Cancer, Goyang 10302, Korea \\ * Correspondence: mckook@ncc.re.kr (M.-C.K.); docryu@ncc.re.kr (K.W.R.) \\ + These authors contributed equally to this work.
}

Received: 8 September 2020; Accepted: 29 September 2020; Published: 2 October 2020

check for updates

Simple Summary: Clinicopathological features and immunohistochemical subtype were evaluated in patients with remnant gastric cancer considering the initial cause of partial gastrectomy. In the malignant group, the proportion of male patients was substantially lower, with a shorter interval between initial partial gastrectomy and remnant gastric cancer. In the background mucosa around the carcinomas, incidence of high-grade pyloric metaplasia was significantly higher in the benign group (13/20, $65.0 \%$ vs. $10 / 28,35.7 \%)$, while high-grade intestinal metaplasia was only observed in the malignant group $(0 / 20,0 \%$ vs. $7 / 28,25.0 \%)$. The pathogenesis of remnant gastric cancer may differ depending on the initial disease. Benign disease was prevalently associated with pyloric metaplasia. Malignant disease was also accompanied by intestinal metaplasia.

Abstract: Background: The incidence of gastric cancer increases in the remnant stomach after partial
gastrectomy; however, its pathogenesis remains controversial. The clinicopathological features and
immunohistochemical subtype were evaluated in patients with remnant gastric cancer considering
the initial cause of partial gastrectomy. Methods: We categorized 59 cases of remnant gastric cancer
who underwent curative surgery between 2001 and 2016 according to initial pathologies of benign
$(n=24)$ or malignant $(n=35)$. Histological changes including pyloric metaplasia and intestinal
metaplasia in the mucosa around the anastomosis site and the background mucosa of carcinomas were
compared between the groups. Results: In the malignant group, the proportion of male patients was
substantially lower, with a shorter interval. In background mucosa around the carcinomas, incidence
of high-grade pyloric metaplasia was significantly higher in the benign group (13/20, $65.0 \%$ vs. $10 / 28$,
$35.7 \%)$, while high-grade intestinal metaplasia was only observed in the malignant group $(0 / 20,0 \%$
vs. $7 / 28,25.0 \%)$. Conclusions: The cancers in the initial benign disease are mainly associated with
pyloric metaplasia at the anastomosis site, reflecting reflux, but not with intestinal metaplasia. On the
other hand, in the initial malignant disease group, intestinal metaplasia has an equally important role
as reflux-associated pyloric metaplasia.

Keywords: remnant gastric cancer; partial gastrectomy; pyloric metaplasia; intestinal metaplasia; pathogenesis 


\section{Introduction}

Early diagnosis of gastric cancer according to national screening programs and advanced surgical treatment have led to an increase in the five-year survival rates in Korea and Japan [1-3]. Gastric resection with lymph node dissection is the only curative treatment for these patients [4]. Metachronous cancer in the remnant stomach after partial gastrectomy has gained great interest due to the increased application of organ function-preserving surgery [5].

The hypothesized risk factors for remnant gastric cancer include Helicobacter pylori (H. pylori) infection, changes in the gastric mucosa due to bile reflux, and the type of anastomosis methods [6-8]. However, most of these studies are retrospective and disease incidence and pathogenesis were not investigated. Several studies have reported that the changes in gastric mucosa caused by bile reflux after subtotal gastrectomy may increase the prevalence of remnant gastric cancer. This was in contrast to the results of other studies reporting that bile reflux may decrease $H$. pylori infection and generated a controversy about the relevant risk factors $[9,10]$. In order to understand the risk factors and features of remnant gastric cancer, combined pathological analysis of the anastomosis site and background mucosa is required. However, to date, very few studies have addressed this issue.

Recent studies have suggested new molecular classifications of gastric cancer, aimed at improving prognosis and treatment [11,12]. Presumably, a better understanding of the changes occurring in the anastomosis mucosa, as well as molecular subtype classification based on immunohistochemistry, will shed light on the pathogenesis of remnant gastric cancer.

In this study, patients diagnosed with remnant gastric cancer who had undergone surgery were classified based on the initial disease after partial gastrectomy. The analysis of clinicopathological features and mucosal changes, as well as the immunohistochemical evaluation of molecular subtypes, were carried out to investigate the pathogenesis of remnant gastric cancer.

\section{Materials and Methods}

\subsection{Inclusion Criteria and Clinical Characteristics}

Patients who underwent surgery for remnant gastric cancer at the National Cancer Center, Korea, from 2001 to 2016 were divided into a benign and a malignant group based on the reason for partial gastrectomy. In the case of remnant gastric cancer from residual disease of initial surgery, the recurrence within 5 years of surgery was excluded. In order to compare histologically in the same manner as the malignancy group, cases with anastomosis at an antrum on previous surgeries were excluded. Remnant gastric cancer was diagnosed by endoscopy and computed tomography (CT) prior to surgery. Ethical approval for the research protocol was provided by the institutional review board of the National Cancer Center (No. NCC2018-0207). The need for and patients' informed consent was waived with approval of Institutional Review Board given the retrospective nature of the study.

The following clinical factors were evaluated: sex, age, H. pylori infection status, interval between initial partial gastrectomy and remnant gastric cancer surgery, initial surgical method, stage of malignancy at initial partial gastrectomy, pathological stage after surgery, histology, and Lauren classification.

\subsection{Pathological Analysis}

To evaluate the cumulative effects of the reflux, foveolar hyperplasia (FH) [9] and pyloric metaplasia (PM) [13] were examined in the anastomosis area. In order to selectively focus on PM caused by reflux, excluding the effect of antralization [14], only the part without intestinal metaplasia (IM) was considered as PM. Based on PM distribution, the PM grade in the anastomosis area was determined for the zone within $3 \mathrm{~cm}$ from the anastomosis junction (see the Results section).

To identify preneoplastic changes possibly related to carcinogenesis, the pathological features of the background mucosa surrounding the carcinomas were analyzed. The background mucosa was 
classified as normal-type when both PM and intestinal metaplasia were grade 0 or 1 , as PM-type when PM was grade 2 or 3, and as intestinal metaplasia-type when intestinal metaplasia was grade 2 or 3.

The grade of metaplasia in the anastomosis area or the background mucosa was assigned using criteria of the Updated Sydney system. Briefly, grading is performed using the four-tiered grading system $(0,1,2,3)$ and the cut-off points of grade $1(\leq 30 \%)$, grade $2(31-60 \%)$, and grade $3(\geq 61 \%)[9,15]$.

\subsection{Immunohistochemistry Analysis}

The Epstein-Barr virus status, microsatellite instability, mucin phenotype, as well as the expression of E-cadherin, aberrant P53, aberrant HER-2, aberrant MET, and CDX2, were compared between the benign and the malignant group (Figure 1). Immunohistochemistry results were segregated based on the molecular The Cancer Genome Atlas (TCGA) classification [12,16].

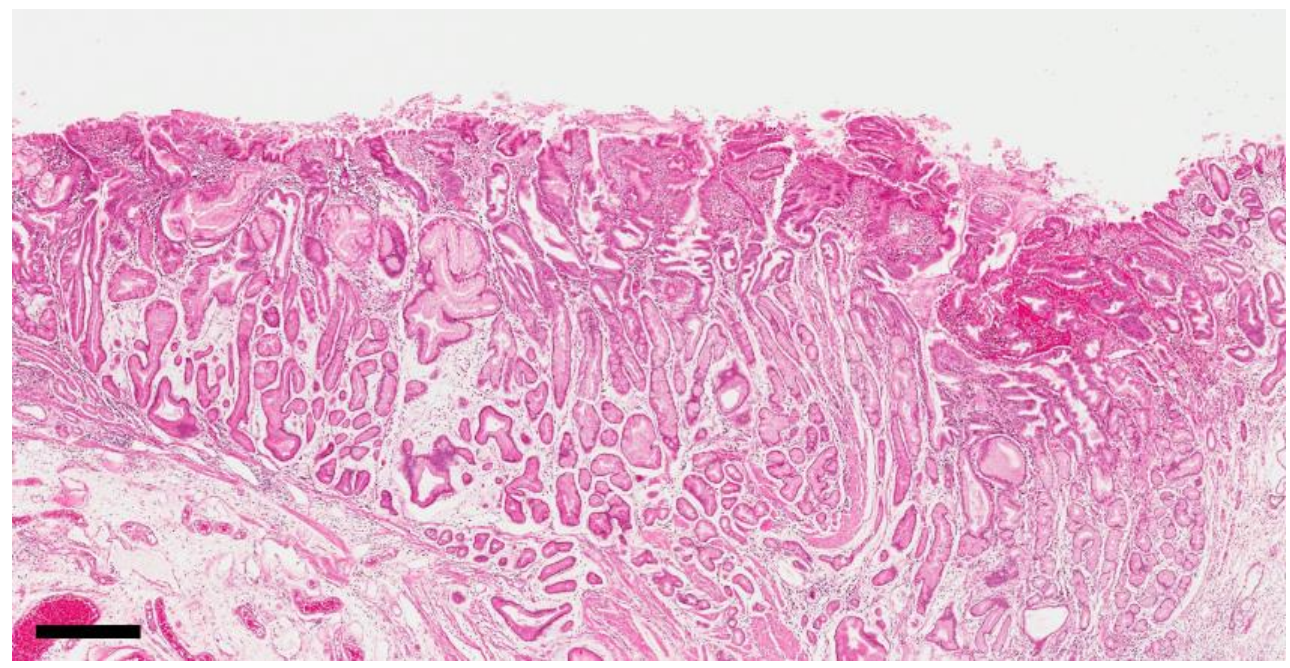

Figure 1. Reflux-induced changes in the anastomosis area. The upper epithelial layer showed foveolar hyperplasia and the lower glandular layer showed pyloric metaplasia in the absence of intestinal metaplasia. (magnification 40×). Scale bar represents $500 \mu \mathrm{m}$.

\subsection{Statistical Analysis}

Continuous variables were presented as mean \pm standard error and categorical variables were expressed as proportions. Categorical variables were compared using the Pearson $\chi^{2}$ test, while continuous variables were compared using the t-test or Mann-Whitney $U$ test, as appropriate. The threshold for statistical significance was set at $p<0.05$. All statistical analyses were performed using SAS version 9.1.3 for Windows (SAS Institute, Cary, NC, USA).

\section{Results}

\subsection{Patient Demographics}

In total, 59 patients were included in this study. Of these, 24 (most of whom had undergone ulcer surgery) were assigned to the benign group, and 35 were included in the malignant group, mainly after surgery for gastric adenocarcinoma. The malignant group included a lower number of male patients and was characterized by a shorter time interval between initial partial gastrectomy and remnant gastric cancer diagnosis. The cases of $H$. pylori infection were more abundant in the benign group, but the difference was not statistically significant $(62.5 \%$ vs. $31.4 \%, p=0.17)$ (Table 1$)$.

\subsection{Distribution of Reflux-Induced Mucosal Changes in the Anastomosis Area}

For 41 cases, sections of non-neoplastic mucosa in the anastomosis area were available for analysis. FH and PM, which are hallmarks of reflux gastritis, were observed in most cases (37/41 and 38/41, 
respectively). Two changes occurred simultaneously within one gland, with FH on the upper layer and PM on the lower layer (Figure 1). Pyloric-type glands frequently descended to the submucosal layer and formed gastritis cystica profunda. Infiltration of inflammatory cells was very low. FH was distributed up to $5 \mathrm{~cm}$ from the anastomosis junction; in $1 / 3$ of the cases it was distributed within $1.29 \mathrm{~cm}$, whereas in $2 / 3$ of the cases it was distributed up to $2.2 \mathrm{~cm}$ from the anastomosis junction. PM was distributed up to $5 \mathrm{~cm}$ from the anastomosis junction; in $1 / 3$ of the cases it was distributed within $0.8 \mathrm{~cm}$, whereas in $2 / 3$ of the cases it was distributed within $1.9 \mathrm{~cm}$ from the anastomosis junction (Table 2). Based on these distribution patterns, we defined the severity within the area from the anastomosis junction to $3 \mathrm{~cm}$ as the grade of PM in the anastomosis area.

Table 1. Patient demographic.

\begin{tabular}{|c|c|c|c|c|}
\hline Category & Variables & Benign $(n=24)$ & Malignancy $(n=35)$ & $p$ Value \\
\hline Age (years) & & $63.9 \pm 8.7$ & $65.1 \pm 11.5$ & 0.66 \\
\hline \multirow{2}{*}{ Sex } & Male & $24(100 \%)$ & $27(77.1 \%)$ & \multirow{2}{*}{0.02} \\
\hline & Female & $0(0 \%)$ & $8(22.9 \%)$ & \\
\hline Interval (years) & & $30.1 \pm 8.0$ & $13.4 \pm 6.8$ & $<0.001$ \\
\hline \multirow{3}{*}{ Initial operation } & Billroth I & $0(0 \%)$ & $7(20 \%)$ & \multirow{2}{*}{0.06} \\
\hline & Billroth II & $24(100 \%)$ & $28(80 \%)$ & \\
\hline & I & & $24(68.6 \%)$ & \\
\hline \multirow{4}{*}{$\begin{array}{l}\text { Pathologic stage of } \\
\text { initial adenocarcinoma }\end{array}$} & II & & $3(8.6 . \%)$ & \\
\hline & III & - & $1(2.9 \%)$ & \\
\hline & IV & & $0(0 \%)$ & \\
\hline & unknown & & $7(20.0 \%)$ & \\
\hline \multirow{4}{*}{$\begin{array}{l}\text { Pathologic Stage of } \\
\text { remnant cancer }\end{array}$} & I & $13(54.2 \%)$ & $19(54.3 \%)$ & \multirow{4}{*}{0.71} \\
\hline & II & $6(25.0 \%)$ & $10(28.6 \%)$ & \\
\hline & III & $4(16.7 \%)$ & $6(17.1 \%)$ & \\
\hline & IV & $1(4.2 \%)$ & $0(0 \%)$ & \\
\hline & Negative & $15(62.5 \%)$ & $25(71.4 \%)$ & \multirow{2}{*}{0.47} \\
\hline LN metastasis & Positive & $9(37.5 \%)$ & $10(28.6 \%)$ & \\
\hline Tumor size & & $4.6 \pm 2.1$ & $4.4 \pm 2.4$ & 0.52 \\
\hline \multirow{3}{*}{ Histology } & Differentiated & $15(62.5 \%)$ & $16(45.7 \%)$ & \multirow{3}{*}{0.2} \\
\hline & Undifferentiated & $9(37.5 \%)$ & $19(54.3 \%)$ & \\
\hline & Intestinal & $14(58.3 \%)$ & $12(34.3 \%)$ & \\
\hline \multirow{3}{*}{ Lauren classification } & Diffuse & $8(33.3 \%)$ & $17(48.6 \%)$ & \multirow{3}{*}{0.07} \\
\hline & Mixed & $2(8.3 \%)$ & $6(17.1 \%)$ & \\
\hline & Negative & $8(33.3 \%)$ & $21(60.0 \%)$ & \\
\hline \multirow[t]{2}{*}{ H. pylori infection } & Positive & $15(62.5 \%)$ & $11(31.4 \%)$ & \multirow[t]{2}{*}{0.17} \\
\hline & Unknown & $1(4.2 \%)$ & $3(8.6 \%)$ & \\
\hline
\end{tabular}

Table 2. Distribution range of reflux-induced mucosal changes from the anastomosis junction.

\begin{tabular}{ccccc}
\hline Variables & Median & Maximum & 33 Percentile & 67 Percentile \\
\hline Foveolar hyperplasia & $1.3 \mathrm{~cm}$ & $5 \mathrm{~cm}$ & $1.29 \mathrm{~cm}$ & $2.2 \mathrm{~cm}$ \\
Pyloric metaplasia & $1.5 \mathrm{~cm}$ & $5 \mathrm{~cm}$ & $0.8 \mathrm{~cm}$ & $1.9 \mathrm{~cm}$ \\
\hline
\end{tabular}

\subsection{Differences in the Mucosa of the Anastomosis Area between Benign and Malignant Cases}

Tumor classification based on disease severity at the time of initial partial gastrectomy revealed a substantial difference in the anastomosis area. In the benign group, the tumors were located within the distribution distance of $\mathrm{PM}$, whereas in the malignant group, the tumors were located beyond the PM range. While most patients in the benign group exhibited high-grade PM (18/19, 94.7\%), those in the malignant group prevalently displayed low-grade PM (14/22, 63.6\%). Most cases in both groups presented no or mild-grade intestinal metaplasia in the anastomosis area and moderate or higher grades were rarely observed $(2 / 41)$ (Table 3$)$.

\subsection{Differences in the Background Mucosa around the Carcinoma between Benign and Malignant Cases}

For 48 cases, sections of the background mucosa were available for analysis. A significant difference was noted between the groups $(p=0.028)$. In the benign group, most cases exhibited PM 
(13/20, 65.0\%), while intestinal metaplasia (IM) was absent (0/20). The remaining cases exhibited normal mucosa $(7 / 20,35 \%)$. The malignant group exhibited all three mucosal types at a similar frequency (PM: 10/28, 35.7\%; intestinal metaplasia: 7/28, 25.0\%; normal mucosa: 11/28, 39.3\%) (Table 4).

Table 3. Tumor location and the mucosal characters of anastomosis area.

\begin{tabular}{|c|c|c|c|c|}
\hline Variables & Grade & Benign $(n=19)$ & Malignancy $(n=22)$ & $p$-Value \\
\hline $\begin{array}{l}\text { Distance from } \\
\text { tumor center to } \\
\text { anastomosis }(\mathrm{cm})\end{array}$ & & $1.80 \pm 0.57$ & $2.98 \pm 0.53$ & 0.14 \\
\hline Length of $\mathrm{PM}$ * & & $2.3 \pm 0.27$ & $0.85 \pm 0.15$ & $<0.001$ \\
\hline PM grade & $\begin{array}{c}\text { Low (grade } 0,1 \text { ) } \\
\text { High (grade } 2,3 \text { ) }\end{array}$ & $\begin{array}{c}1(5.3 \%) \\
18(94.7 \%)\end{array}$ & $\begin{array}{c}14(63.6 \%) \\
8(36.4 \%)\end{array}$ & $<0.001$ \\
\hline IM * grade & $\begin{array}{l}\text { Low (grade } 0,1 \text { ) } \\
\text { High (grade } 2,3 \text { ) }\end{array}$ & $\begin{array}{c}19(100 \%) \\
0\end{array}$ & $\begin{array}{c}20(91 \%) \\
2(9 \%)\end{array}$ & 0.927 \\
\hline
\end{tabular}

* PM: pyloric metaplasia, IM: intestinal metaplasia.

Table 4. Differences between the types of background mucosa surrounding carcinomas.

\begin{tabular}{cccc}
\hline Mucosal Type & Benign $(\boldsymbol{n = 2 0 )}$ & Malignancy $(\boldsymbol{n}=\mathbf{2 8 )}$ & $\boldsymbol{p}$-Value \\
\hline Normal mucosa & $7(35.0 \%)$ & $11(39.3 \%)$ & \\
Pyloric metaplasia & $13(65.0 \%)$ & $10(35.7 \%)$ & 0.028 \\
Intestinal metaplasia & $0(0 \%)$ & $7(25.0 \%)$ & \\
\hline
\end{tabular}

\subsection{Results of Immunohistochemistry and Molecular Classification}

In total, 52 cases were analyzed by immunohistochemistry. Molecular classification according to immunohistochemistry confirmed a significant prevalence of the Epstein-Barr virus (EBV) type in the benign group $(7 / 22,31.8 \%$ vs. $1 / 33,3.0 \%)$. Moreover, a relatively high frequency of aberrant P53 $(6 / 22,27.3 \%$ vs. $10 / 33,30.3 \%)$, as well as another type $(9 / 22,42.9 \%$ vs. $19 / 33,57.6 \%)$ was observed in the malignant group, albeit the latter differences were not statistically significant. CDX2 expression was predominant in the malignant group $(11 / 22,50.0 \%$ vs. $26 / 33,78.8 \% ; p=0.014)$ (Table 5$)$.

Table 5. Classification based on immunohistochemistry and in situ hybridization.

\begin{tabular}{|c|c|c|c|c|}
\hline Variables & Classification & Benign $(n=22)$ & Malignancy $(n=33)$ & $p$ Value \\
\hline \multirow{5}{*}{ Molecular type } & EBV type & $7(31.8 \%)$ & $1(3.0 \%)$ & \multirow{2}{*}{0.068} \\
\hline & MSI type & 0 & $3(9.1 \%)$ & \\
\hline & $\begin{array}{l}\text { E-cadherin } \\
\text { aberrant type }\end{array}$ & $1(4.5 \%)$ & $1(3.0 \%)$ & \\
\hline & P 53 aberrant type & $6(27.3 \%)$ & $10(30.3 \%)$ & \\
\hline & Other type * & $9(42.9 \%)$ & $19(57.6 \%)$ & \\
\hline \multirow{2}{*}{ HER-2 aberrant } & Negative & $22(100.0 \%)$ & $29(87.9 \%)$ & \multirow{2}{*}{0.106} \\
\hline & Positive & $0(0.0 \%)$ & $4(12.1 \%)$ & \\
\hline \multirow{2}{*}{ MET aberrant } & Normal & $12(54.5 \%)$ & $23(66.7 \%)$ & \multirow{3}{*}{0.404} \\
\hline & Abnormal & $10(45.5 \%)$ & $10(33.3 \%)$ & \\
\hline \multirow{3}{*}{ Mucin phenotype } & Gastric type & $7(31.8 \%)$ & $10(30.3 \%)$ & \\
\hline & $\begin{array}{c}\text { Gastric-intestinal } \\
\text { type }\end{array}$ & $5(22.7 \%)$ & $10(30.3 \%)$ & \multirow[t]{2}{*}{0.827} \\
\hline & Intestinal type & $4(18.2 \%)$ & $6(18.2 \%)$ & \\
\hline \multirow{3}{*}{ CDX2 expression } & Null type & $6(27.2 \%)$ & $7(21.3 \%)$ & \multirow{3}{*}{0.014} \\
\hline & Negative & $11(50.0 \%)$ & $7(21.2 \%)$ & \\
\hline & Positive & $11(50.0 \%)$ & $26(78.8 \%)$ & \\
\hline
\end{tabular}

* Other type: Normal P53 expression with lack of Epstein-Barr virus (EBV), microsatellite instability (MSI) deficiency, and E-cadherin aberrant. 


\section{Discussion}

Numerous studies have described the clinical features of remnant gastric cancer. However, the pathogenesis and cause of the disease remains controversial. Moreover, little is known regarding the histological features of the anastomosis site and background mucosa in remnant gastric cancer. The present study investigated the clinical features of remnant gastric cancer based on initial disease of partial gastrectomy. In addition, histological analysis and molecular classification based on immunohistochemistry were conducted to investigate the pathogenesis of remnant gastric cancer. Remnant gastric cancers that occurred following benign disease were strongly associated with PM of the anastomosis site, whereas malignant remnant gastric cancers were characterized by both PM and intestinal metaplasia.

In accordance with previous studies, a significant difference was observed between the benign and the malignant group in the duration of the interval between the initial partial gastrectomy and the occurrence of remnant gastric cancer. Numerous studies have hypothesized that the shorter interval in the malignant group is related to the presence of a precancerous lesion, such as atrophic gastritis and intestinal metaplasia $[17,18]$.

Reflux gastritis from bile may occur in the remnant stomach and its major histological feature is known as FH without inflammation [9]. In the present study, we analyzed the distribution and severity of reflux gastritis in detail. PM, in addition to FH, was observed around the anastomosis site. These characteristics of PM were frequently observed in the remnant stomach. On the other hand, the literature focusing on PM in the remnant stomach is extremely poor [13]. PM is a phenomenon by which fundic-type glands transform into mucin-secreting pyloric-type glands, and has been reported to occur in two forms. One is "antralization", in which PM occurs in the fundic glands of the angle of stomach and gradually progresses toward the proximal part. As a result, the border of the fundic and pyloric mucosa (fundic-pyloric border) also moves toward the proximal part [19]. This phenomenon is associated with H. pylori gastritis and is usually accompanied by IM [14]. The other mechanism is "spasmolytic polypeptide-expressing metaplasia (SPEM)," which occurs separately as a spot within the fundic mucosa region, arises from chief cell transdifferentiation, and further progresses into IM [20]. Whether these two conditions are related remains unclear. PM observed in the present study exhibited distinct characteristics from the two aforementioned mechanisms. First, it started from the anastomosis site of the remnant stomach after partial gastrectomy. Second, it was accompanied by FH, which is a characteristic of reflux gastritis. Third, it was not accompanied by IM.

We demonstrated that PM was the main preneoplastic change in the benign group. A previous study also reported PM in the remnant stomach. However, the relationship between PM and the initial disease status was not clarified, nor was the time interval from initial surgery evaluated [13]. In the latter study, only the presence or absence of PM was recorded, but its grade was not taken into consideration. In the present study, we demonstrated that although PM was present in almost all examined cases, its degree of severity was much higher in the benign group. High-grade PM was prevalent in the mucosa around the carcinomas in the benign group, while its incidence was much lower in the malignant group. This suggested that reflux-induced changes had a stronger impact on the carcinogenic background in the benign group than in the malignant group.

Notably, high-grade IM was only observed in the mucosa of the malignant cases. High-grade IM is the result of mucosal changes due to prolonged H. pylori gastritis. Therefore, H. pylori gastritis and reflux-induced gastritis could have a similar influence on carcinoma development in the malignant group. It can be assumed that partial gastrectomy in the benign group was performed before H. pylori gastritis could progress into the body and, therefore, background mucosa had no chance to develop.

Significant differences in EBV and CDX2 expression were found between the two groups, as determined by immunohistochemistry. EBV-type gastric cancer was highly represented in the benign group (31.8\%), while it was only present in only $3 \%$ of the malignant cases, which is lower than the average incidence among total gastric cancers (5-10\%) [21,22]. EBV-type gastric cancer exhibits unique molecular alterations [16]. However, the mechanism of its development is not well-established. 
EBV-type gastric cancer is highly prevalent in the cardia and body among remnant gastric cancers, but it has no relationship with $H$. pylori infection $[23,24]$. In a recent study, the EBV infection rate was higher in patients with remnant gastric cancer compared with those with conventional gastric cancer. It has been reported that Billroth II anastomosis, carcinoma at the anastomosis site, diffuse type, and EBV genome polymorphisms are related to the EBV-associated remnant gastric cancer [25]. In the present study, EBV-type gastric cancer was higher in the benign group compared to the malignant group, and this may be related to the Billroth II anastomosis in all benign groups. CDX2 was poorly expressed in the benign group, and this could be related to the low grade of IM in the background mucosa of benign cases [26]. CDX2 is a homeobox gene expressed in the intestinal mucosa and has a role in the differentiation of intestinal epithelium [27]. CDX2 is expressed in all gastric carcinomas that develop an intestinal phenotype, but it is also present in a proportion of cases with gastric phenotype [28]. The clinical relevance of the different molecular subtypes of gastric carcinoma is not clear at present, but carcinogenic factors might differ depending on the initial disease.

In the malignant group, remnant gastric cancer occurs after 5 years or more, and at the time of diagnosis, about $50 \%$ is stage II or higher (Figure S1). Annual endoscopic surveillance after gastrectomy in the malignant group should be recommended in at least 10 years, rather than the 5- year follow-up. Meanwhile high-grade pyloric metaplasia was mainly distributed within $3 \mathrm{~cm}$ in the benign group (Figure S2). Considering the data of the present study, it could be suggested to carefully observe the anastomosis area (within $3 \mathrm{~cm}$ ) in the endoscopic surveillance 10 years from the partial gastrectomy performed for the benign cause. (Figure 2)

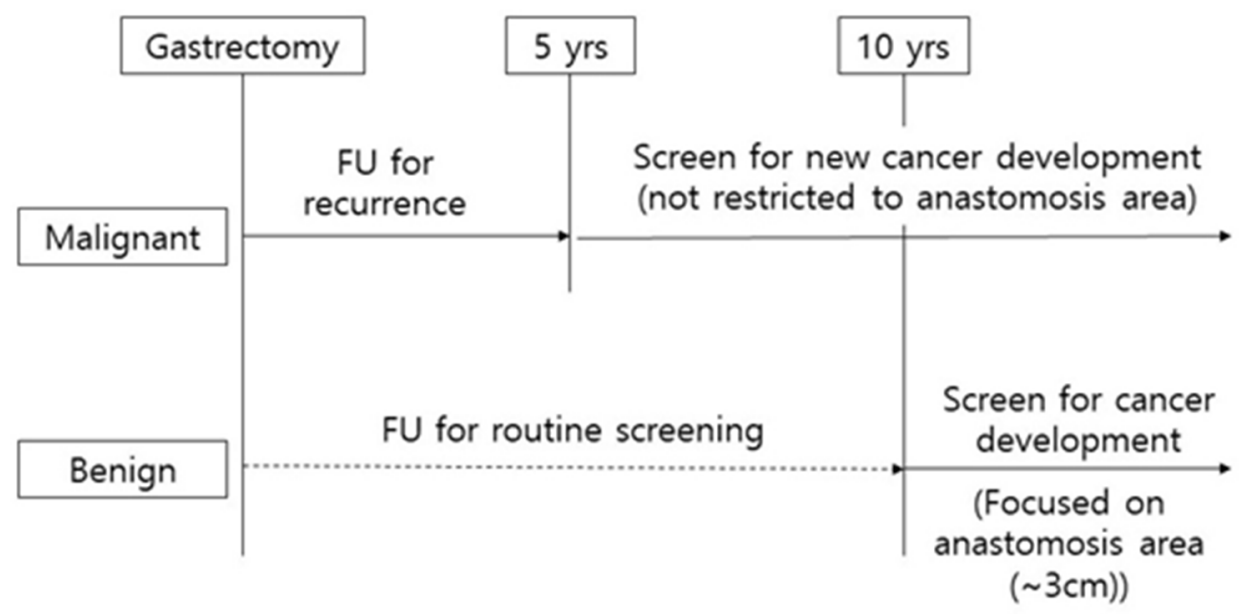

Figure 2. Scheme of clinical surveillance for remnant gastric cancer.

The main limitations of this study are its retrospective design and the relatively small number of cases; the examined sections of some cases were unavailable for the histological analysis of the anastomosis site. In addition, the pathogenic role of background mucosa would be more accurately analyzed if only small-sized cancers were included for analysis. These issues need to be addressed in future studies.

\section{Conclusions}

In conclusion, remnant gastric cancers following benign disease were prevalently associated with $\mathrm{PM}$ of the anastomosis site, whereas those developing after malignant disease were also accompanied by IM. The pathogenesis of remnant gastric cancer may differ depending on the initial disease for partial gastrectomy.

Supplementary Materials: The following are available online at http://www.mdpi.com/2072-6694/12/10/2847/s1, Figure S1: Cumulative incidence of remnant gastric cancer, Figure S2: Scatter plot of remnant gastric cancer according to interval and distance from anastomosis site. 
Author Contributions: W.H.H., manuscript writing, performing procedures and data analysis; K.W.R., M.-C.K., manuscript writing, drafting conception and design; B.W.E., H.M.Y., Y.-W.K., contribution to data collection, data analysis, data interpretation. All authors were involved in writing the paper and had final approval of the submitted and published versions. All authors have read and agreed to the published version of the manuscript.

Funding: This research was funded by National Cancer Center: NCCCDA2018-05; National Cancer Center: NCC Grant 2010150-1; National Cancer Center: NCC Grant 1710360.

Conflicts of Interest: The authors declare no conflict of interest.

\section{References}

1. Information Committee of Korean Gastric Cancer Association. Korean Gastric Cancer Association Nationwide Survey on Gastric Cancer in 2014. J. Gastric Cancer 2016, 16, 131-140. [CrossRef] [PubMed]

2. Allemani, C.; Matsuda, T.; Di Carlo, V.; Harewood, R.; Matz, M.; Niksic, M.; Bonaventure, A.; Valkov, M.; Johnson, C.J.; Esteve, J.; et al. Global surveillance of trends in cancer survival 2000-14 (CONCORD-3): Analysis of individual records for 37513025 patients diagnosed with one of 18 cancers from 322 population-based registries in 71 countries. Lancet 2018, 391, 1023-1075. [CrossRef]

3. Katai, H.; Ishikawa, T.; Akazawa, K.; Isobe, Y.; Miyashiro, I.; Oda, I.; Tsujitani, S.; Ono, H.; Tanabe, S.; Fukagawa, T.; et al. Five-year survival analysis of surgically resected gastric cancer cases in Japan: A retrospective analysis of more than 100,000 patients from the nationwide registry of the Japanese Gastric Cancer Association (2001-2007). Gastric Cancer 2017, 14, 144-154. [CrossRef] [PubMed]

4. Development Working Group \& Review Panel Guideline Committee of the Korean Gastric Cancer Association (KGCA) Korean Practice Guideline for Gastric Cancer 2018: An Evidence-based, Multi-disciplinary Approach. J. Gastric Cancer 2019, 19, 1-48.

5. Ohyama, S.; Tokunaga, M.; Hiki, N.; Fukunaga, T.; Fujisaki, J.; Seto, Y.; Yamaguchi, T. A clinicopathological study of gastric stump carcinoma following proximal gastrectomy. Gastric Cancer 2009, 12, 88-94. [CrossRef]

6. Lee, Y.; Tokunaga, A.; Tajiri, T.; Masuda, G.; Okuda, T.; Fujita, I.; Kiyama, T.; Yoshiyuki, T.; Kato, S.; Matsukura, N.; et al. Inflammation of the gastric remnant after gastrectomy: Mucosal erythema is associated with bile reflux and inflammatory cellular infiltration is associated with Helicobacter pylori infection. J. Gastroenterol. 2004, 39, 520-526. [CrossRef]

7. Choi, I.J.; Kook, M.-C.; Kim, Y.-I.; Cho, S.-J.; Lee, J.Y.; Kim, C.G.; Park, B.; Nam, B.H. Helicobacter pylori Therapy for the Prevention of Metachronous Gastric Cancer. N. Engl. J. Med. 2018, 378, 1085-1095. [CrossRef]

8. Chan, D.-C.; Fan, Y.-M.; Lin, C.-K.; Chen, C.-J.; Chen, C.-Y.; Chao, Y.-C. Roux-en-Y Reconstruction after Distal Gastrectomy to Reduce Enterogastric Reflux and Helicobacter pylori Infection. J. Gastrointest. Surg. 2007, 11, 1732-1740. [CrossRef]

9. Dixon, M.F.; O'Connor, H.J.; Axon, A.T.; King, R.F.; Johnston, D. Reflux gastritis: Distinct histopathological entity? J. Clin. Pathol. 1986, 39, 524-530. [CrossRef]

10. Onoda, N.; Maeda, K.; Sawada, T.; Wakasa, K.; Arakawa, T.; Chung, K.H.-Y.-S. Prevalence of Helicobacter pylori infection in gastric remnant after distal gastrectomy for primary gastric cancer. Gastric Cancer 2001, 4, 87-92. [CrossRef]

11. Cristescu, R.; Lee, J.; Nebozhyn, M.; Kim, K.; Ting, J.C.; Wong, S.S.; Liu, J.; Yue, Y.G.; Wang, J.; Yu, K.; et al. Molecular analysis of gastric cancer identifies subtypes associated with distinct clinical outcomes. Nat. Med. 2015, 21, 449-456. [CrossRef] [PubMed]

12. Setia, N.; Agoston, A.T.; Han, H.S.; Mullen, J.T.; Duda, D.G.; Clark, J.W.; Deshpande, V.; Mino-Kenudson, M.; Srivastava, A.; Lennerz, J.K.; et al. A protein and mRNA expression-based classification of gastric cancer. Mod. Pathol. 2016, 29, 772-784. [CrossRef] [PubMed]

13. Yamaguchi, H.; Goldenring, J.R.; Kaminishi, M.; Lee, J.R. Identification of spasmolytic polypeptide expressing metaplasia (SPEM) in remnant gastric cancer and surveillance postgastrectomy biopsies. Dig. Dis. Sci. 2002, 47, 573-578. [CrossRef] [PubMed]

14. Xia, H.H.-X.; Kalantar, J.S.; Talley, N.J.; Wyatt, J.M.; Adams, S.; Chueng, K.; Mitchell, H.M.; Cheung, K. Antral-type mucosa in the gastric incisura, body, and fundus (antralization): A link between Helicobacter pylori infection and intestinal metaplasia? Am. J. Gastroenterol. 2000, 95, 114-121. [CrossRef] [PubMed] 
15. Kim, S.S.; Kook, M.-C.; Shin, O.-R.; Kim, H.S.; Bae, H.-I.; Park, Y.; Choi, I.J.; Kim, Y.-I.; Nam, B.H.; Kim, S.; et al. Factors to improve the interobserver agreement for gastric atrophy and intestinal metaplasia: Consensus of definition and criteria. Histopathology 2018, 72, 838-845. [CrossRef] [PubMed]

16. The Cancer Genome Atlas Research Network Comprehensive molecular characterization of gastric adenocarcinoma. Nature 2014, 513, 202-209. [CrossRef]

17. Sowa, M.; Kato, Y.; Onoda, N.; Kubo, T.; Maekawa, H.; Yoshikawa, K.; Nishimura, M.; Nakanishi, I.; Chung, Y.S. Early cancer of the gastric remnant with special reference to the importance of follow-up of gastrectomized patients. Eur. J. Surg. Oncol. 1993, 19, 43-49.

18. Ohira, M.; Toyokawa, T.; Sakurai, K.; Kubo, N.; Tanaka, H.; Muguruma, K.; Yashiro, M.; Onoda, N.; Hirakawa, K. Current status in remnant gastric cancer after distal gastrectomy. World J. Gastroenterol. 2016, 22, 2424-2433. [CrossRef]

19. Kimura, K. Chronological Transition of the Fundic-Pyloric Border Determined by Stepwise Biopsy of the Lesser and Greater Curvatures of the Stomach. Gastroenterology 1972, 63, 584-592. [CrossRef]

20. Goldenring, J.R.; Nam, K.T.; Wang, T.C.; Mills, J.C.; Wright, N.A. Spasmolytic Polypeptide-Expressing Metaplasia and Intestinal Metaplasia: Time for Reevaluation of Metaplasias and the Origins of Gastric Cancer. Gastroenterology 2010, 138, 2207-2210.e1. [CrossRef]

21. Kim,H.S.; Shin, S.-J.; Beom, S.-H.; Jung, M.; Choi, Y.Y.; Son, T.; Kim, H.-I.; Cheong, J.-H.; Hyung, W.J.; Noh, S.H.; et al. Comprehensive expression profiles of gastric cancer molecular subtypes by immunohistochemistry: Implications for individualized therapy. Oncotarget 2016, 7, 44608-44620. [CrossRef] [PubMed]

22. Birkman, E.-M.; Mansuri, N.; Kurki, S.; Ålgars, A.; Lintunen, M.; Ristamäki, R.; Sundström, J.; Carpén, O. Gastric cancer: Immunohistochemical classification of molecular subtypes and their association with clinicopathological characteristics. Virchows Arch. 2017, 472, 369-382. [CrossRef] [PubMed]

23. Lee, J.H.; Kim, S.-H.; Han, S.-H.; An, J.-S.; Lee, E.-S.; Kim, Y.-S. Clinicopathological and molecular characteristics of Epstein-Barr virus-associated gastric carcinoma: A meta-analysis. J. Gastroenterol. Hepatol. 2009, 24, 354-365. [CrossRef] [PubMed]

24. Murphy, G.; Pfeiffer, R.; Camargo, M.C.; Rabkin, C.S. Meta-analysis Shows That Prevalence of Epstein-Barr Virus-Positive Gastric Cancer Differs Based on Sex and Anatomic Location. Gastroenterology 2009, 137, 824-833. [CrossRef]

25. Lu, C.; Zhang, H.; Zhou, W.; Wan, X.; Li, L.; Yu, C. Epstein-Barr virus infection and genome polymorphisms on gastric remnant carcinoma: A meta-analysis. Cancer Cell Int. 2020, 20, 1-9. [CrossRef]

26. Almeida, R.; Silva, E.; Santos-Silva, F.; Silberg, D.G.; Wang, J.; De Bolós, C.; David, L. Expression of intestine-specific transcription factors, CDX1 and CDX2, in intestinal metaplasia and gastric carcinomas. J. Pathol. 2002, 199, 36-40. [CrossRef]

27. Mizoshita, T.; Inada, K.-I.; Tsukamoto, T.; Kodera, Y.; Yamamura, Y.; Hirai, T.; Kato, T.; Joh, T.; Itoh, M.; Tatematsu, M. Expression of $\mathrm{Cdx} 1$ and $\mathrm{Cd} \times 2$ mRNAs and relevance of this expression to differentiation in human gastrointestinal mucosa-with special emphasis on participation in intestinal metaplasia of the human stomach. Gastric Cancer 2001, 4, 185-191. [CrossRef]

28. Mizoshita, T.; Tsukamoto, T.; Inada, K.-I.; Ogasawara, N.; Hirata, A.; Kato, S.; Joh, T.; Itoh, M.; Yamamura, Y.; Tatematsu, M. Immunohistochemically detectable Cdx2 is present in intestinal phenotypic elements in early gastric cancers of both differentiated and undifferentiated types, with no correlation to non-neoplastic surrounding mucosa. Pathol. Int. 2004, 54, 392-400. [CrossRef]

(C) 2020 by the authors. Licensee MDPI, Basel, Switzerland. This article is an open access article distributed under the terms and conditions of the Creative Commons Attribution (CC BY) license (http://creativecommons.org/licenses/by/4.0/). 